\title{
كلمة التحرير
}

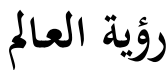

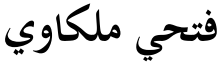

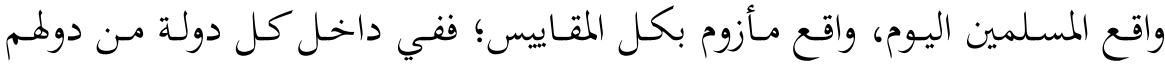

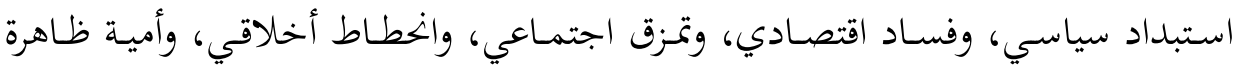

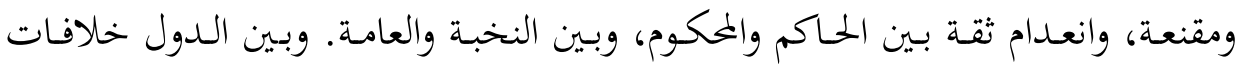

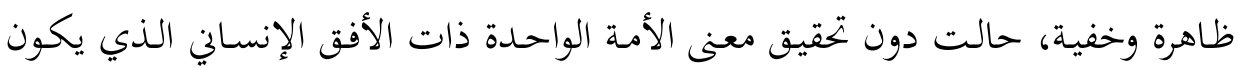
شاهدا على الناس بالحق والعدل والخير.

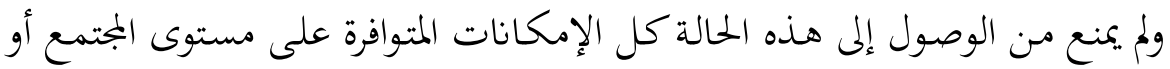

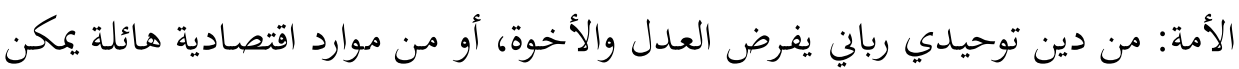

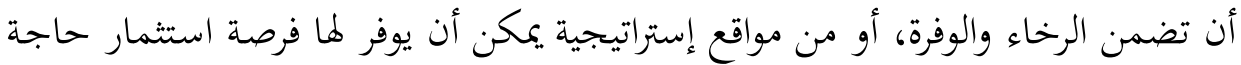
الأمم إليها واحترام هويتها ومصالحها.

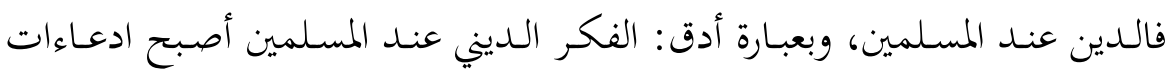

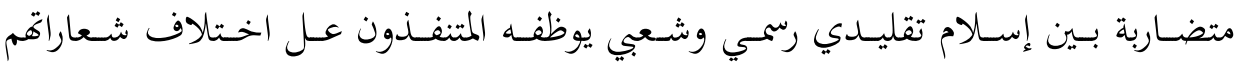
وتوجهاتم، ويستعملونه أداة لمشروعيتهم، وإسلام عصري نخبوي تتوزع على تبنيه فئات

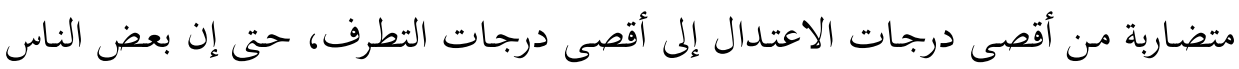

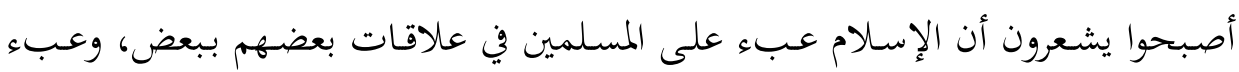

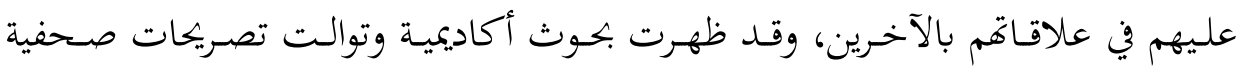


تتساءل عن أسباب التخلف والفوضى التي تعيشها معظم الجُتمعات الإسلامية وتؤكد أو تقترح على الأقل أن مشكلة المسلمين ربما كانت كامنة في إسلامهم.

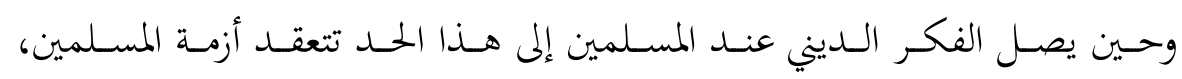

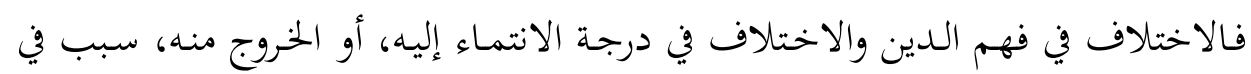

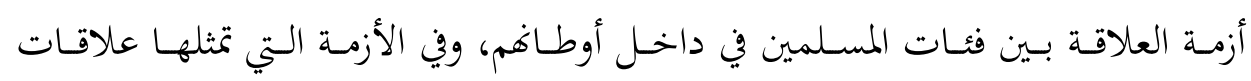

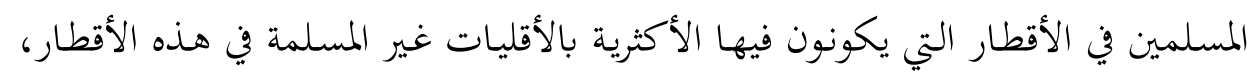

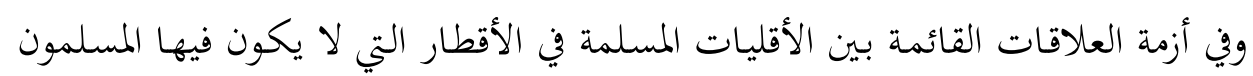

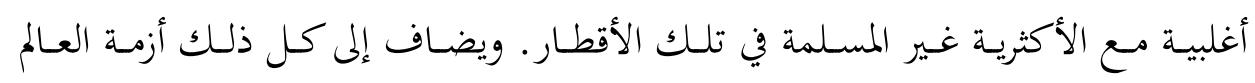
الإسلامي والأمة الإسلامية مع الناس من حولهم في العالم المعاصر.

أما الموارد الاقتصادية الهائلة والمواقع الاستراتيجية الفريدة فقد أصبحت هي الأخرى

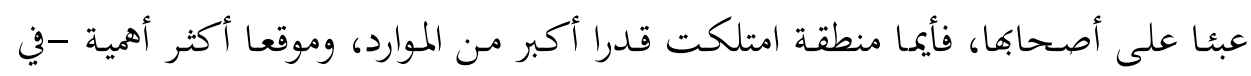

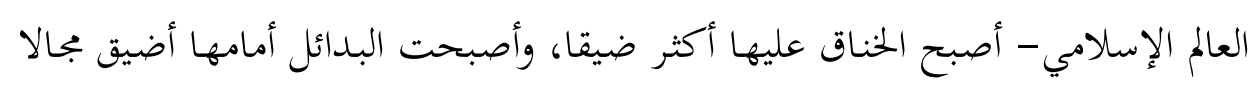

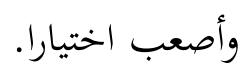

أمسام هـه الصورة المثيرة "الدراماتيكية" وتحت تأثيرهـا يتخيل بعض الناس بأن أزمة

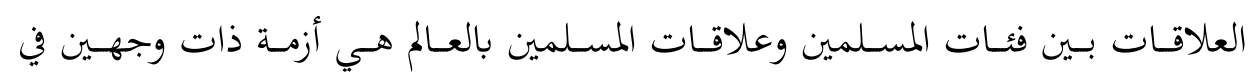

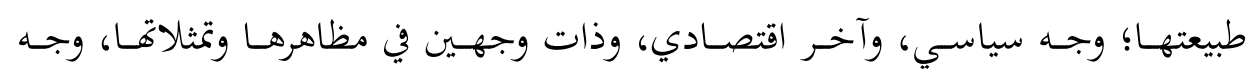

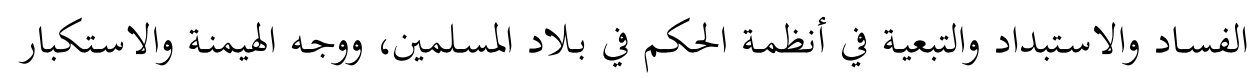
في قوى الهجوم الغربي المعادي للإسلام والمسلمين.

ومن الخطأ أن ننكر الطبيعة السياسية والاقتصادية في أزمة الأمة، ومن الخطأ كذلك أنكانك

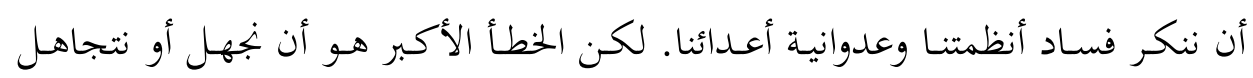

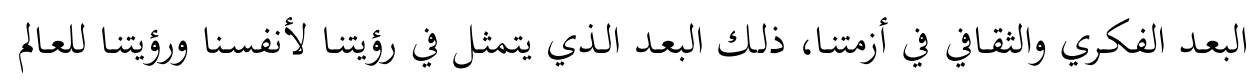
من حولنا. 
وقد تطرقنا إلى مفهوم رؤية العالم وأهميته في عدد من المناسبات، 1 وكان الدلالة التي

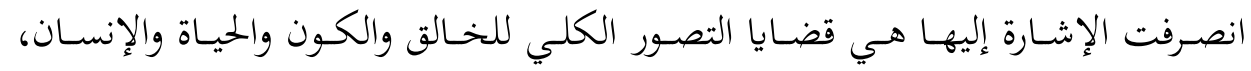

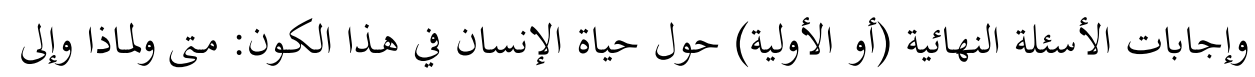

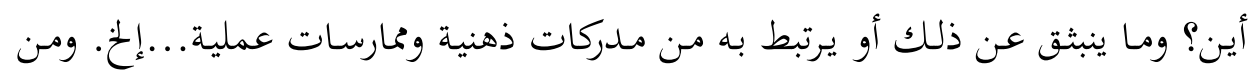

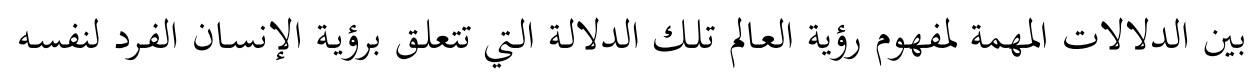

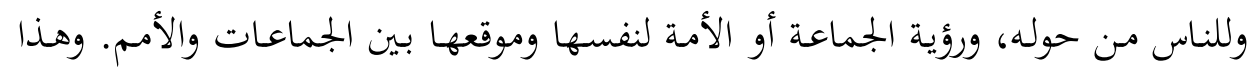
هو موضوع الحديث في هذا المقام.

يرى "رضوان السيد" أنـا نحن المسلمين اليوم: "لا نملك في الفكر العربي الإسلامي

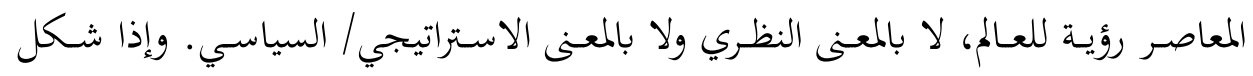

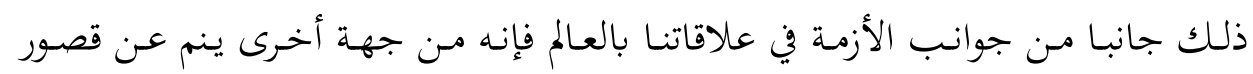

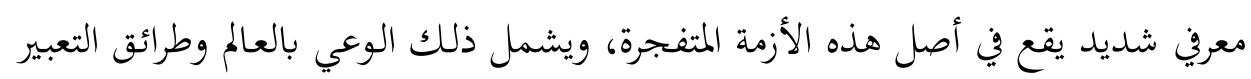

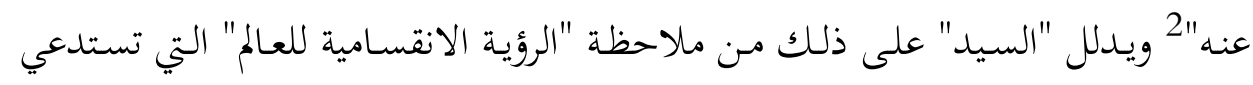

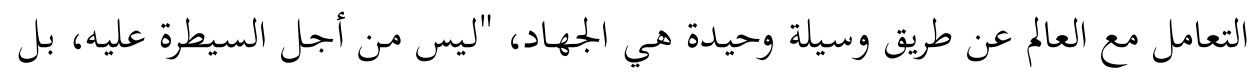

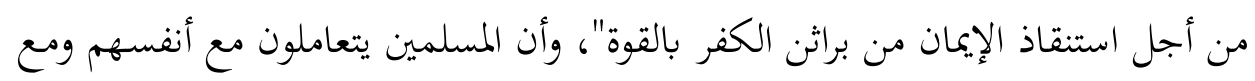

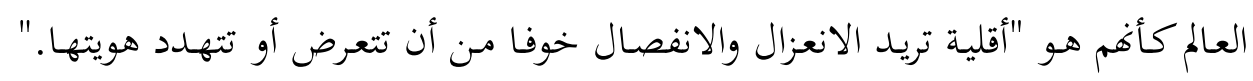

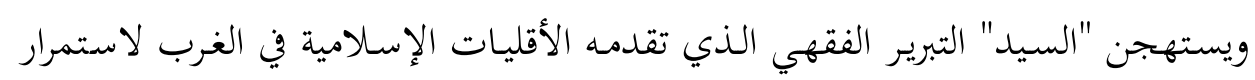

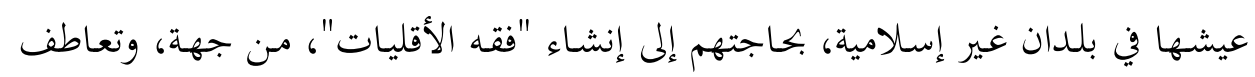

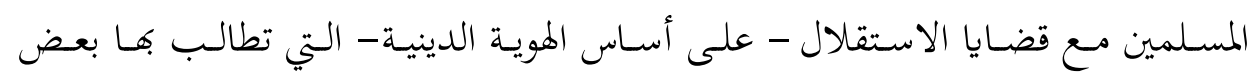

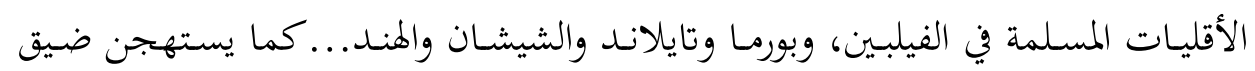

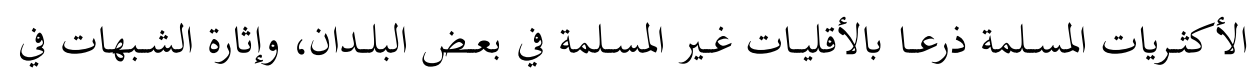
أمانة هذه الأقليات لمجتمعاتما التاريخية الإسلامية.

1 انظر كلمة التحرير في العدد 41، وبحث رؤية العالم والعلوم الاجتماعية في العدد 42-43. 2 السيد، رضوان. الصراع على الإسلام: الأصولية والإصلاح والسياسات الدولية العادية، بيروت: دار الكتاب العربي، 
ويف الوقت الذي لا يتسرع فيه "رضوان السيد" إدانة القلق الإسلامي على مدى العالم بحاه

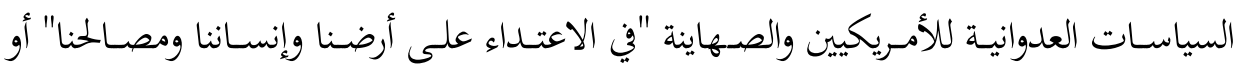

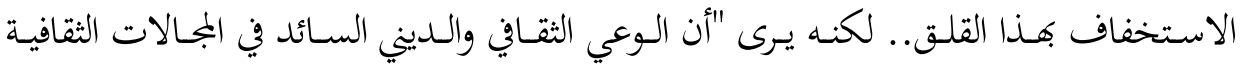

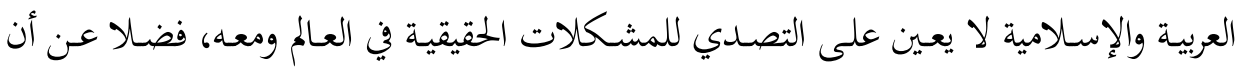

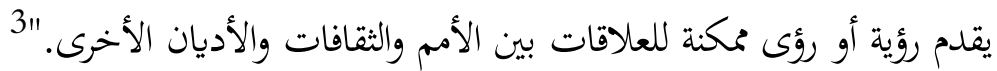
ومن المعروف أن رؤية العالم في هذا السياق كانت جزءا من الفقه الجغرافي للعالم عند

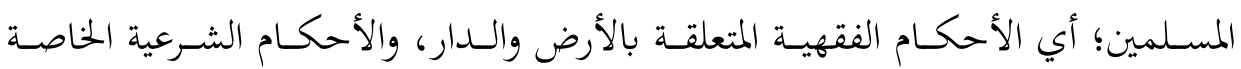
بالإقامة فيها أو الهجرة إليها أو منها. ونغن نشير هنا إلى الفقه والرؤية الفقهية بععناهـا الاصطلاحي القـار، وليس إلى مطلق الفهم بدلالته العامة؛ أي فهم النص في مقاصداه

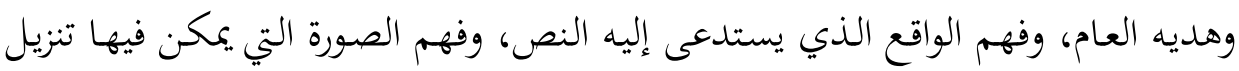
ذلك النص على الواقع لتحقيق مقاصد الهدي الإلهي في حياة الناس. فالرؤية الفقهية كانت جزءا من الفقه السياسي الذي يجكم علاقات المسلمين بغيرهم في

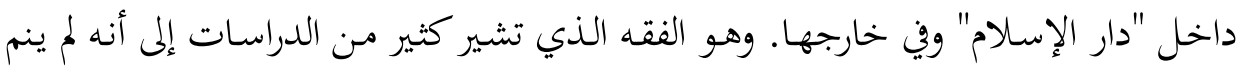

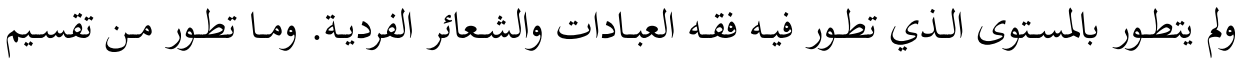

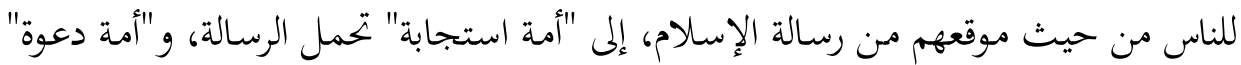

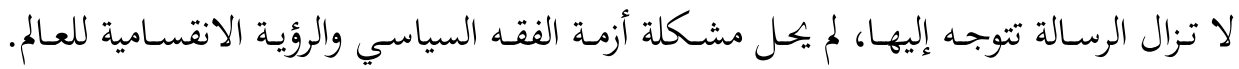

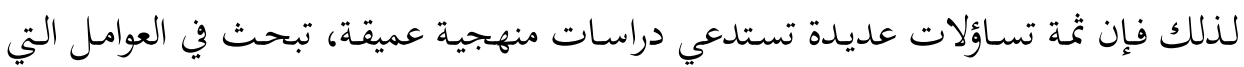

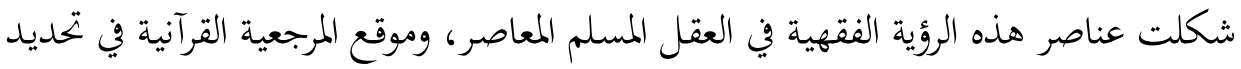

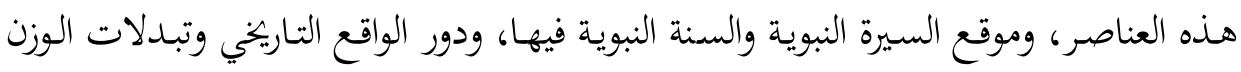

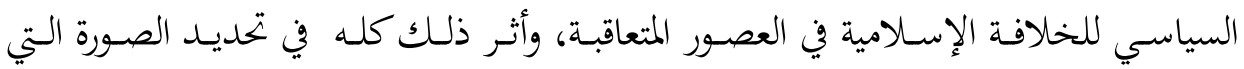

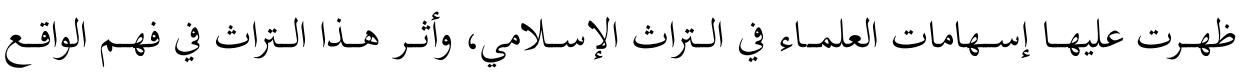

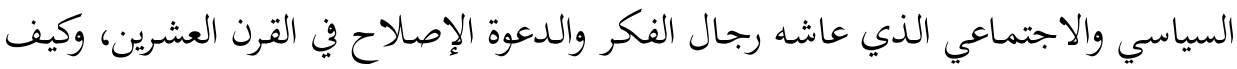


انتهى الأمر إلى ما نشهـه اليوم من استمرار الؤية الفقهية الانقسامية التي تنتمي إلى التراث، وإلى ظهور صور مـ فهم العلاقات بين المسلمين وغيرهم في داخل بـلاد المسلمين التاريخية

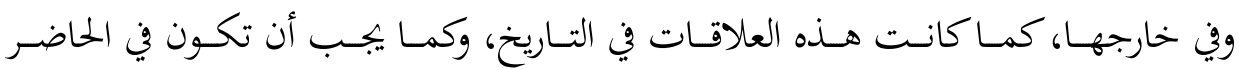
والمستقبل. مثل هذه التساؤلات ليست موضوع هذه الكلمة، وإنما هي موضوع عدد خاص من هذه المجلة سوف يصدر قريبا إن شاء الله.

والذي يعنينا الآن هو التأكيد على ملحوظتين حول الواقع الاجتماعي والسياسي في

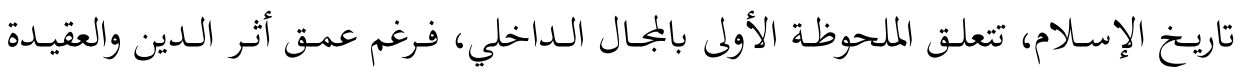
(الملة) -وربما بسبب هذا الأثر - فإن ذلك الواقع التاريخي قد بحاوز الرؤية الفقهية التقليدية، كمـا تبـدو في التراث، وشههد ذلك الواقع -خلافا لتلك الرؤية- تعايشـا بين أبنـاء الملل

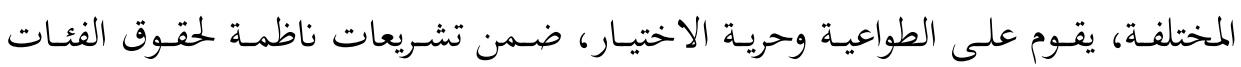
المختلفة، ولم تكن هذه الفئات مضطرة إلى التنبيه على حقوقها وتمايزهـا، ومن ثم إصدار التشريعات التي تعترف بها وبتمايزها وبحقوقها، بل جرى ذلك التأسيس في وقت التشريع

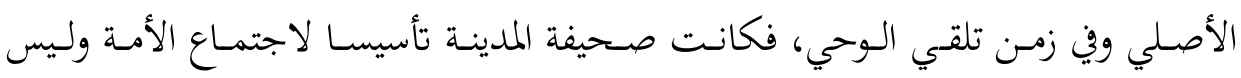

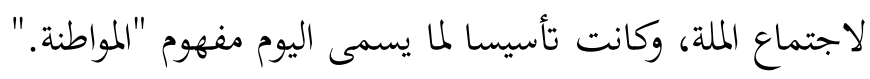

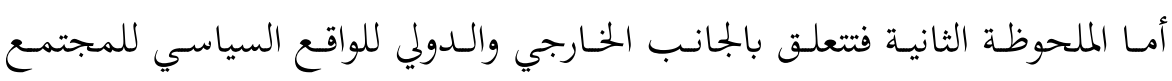
الإسلامي، من حيث الشؤون الخارجية للأمة المسلمة وعلاقاتها الدولية، فلم يقتصر ذلك لكاتك

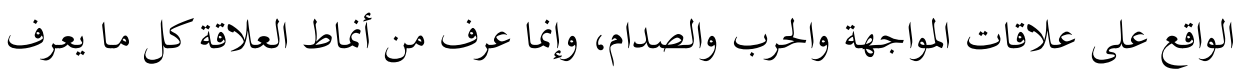

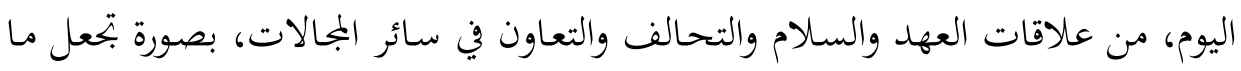

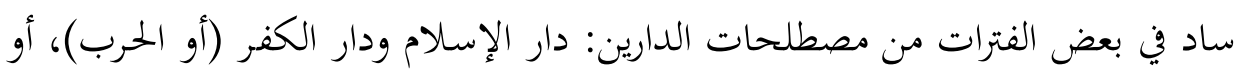
الدور الثلاثة: دار الإسلام ودار الكفر ودار العهد، مجرد مصطلحات فقهية واجتهادات

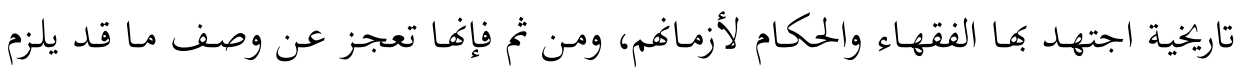

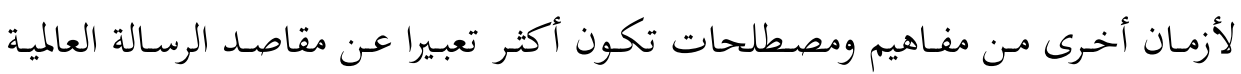




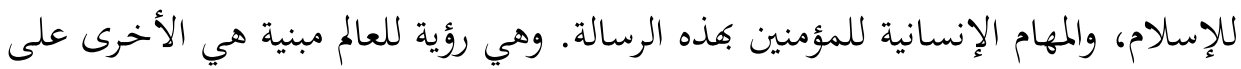

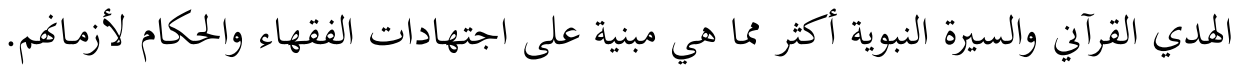

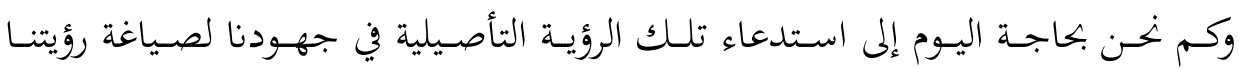
الإسلامية المعاصرة للعالم.

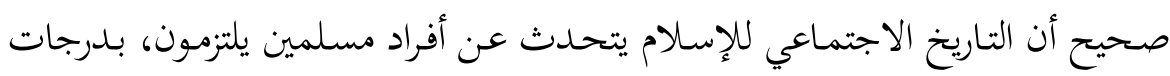

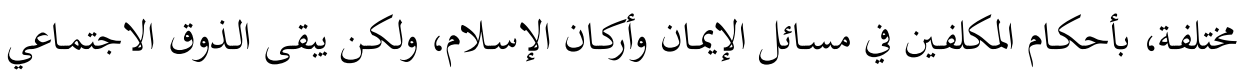

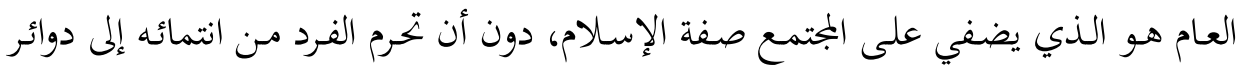

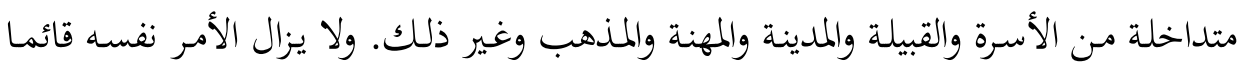

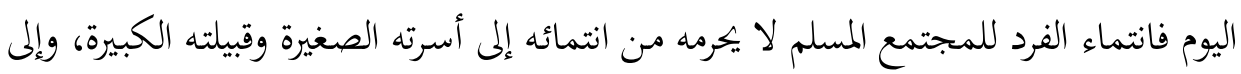

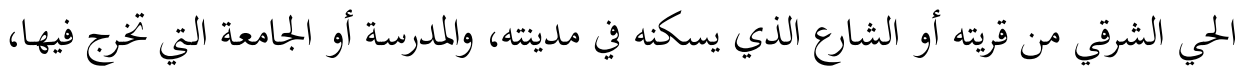

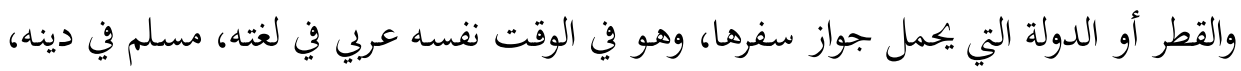
شافعي في مذهبه. وهو في الوقت نفسه ابن عصره الذي يركب السيارة والطائرة، وابن جيله

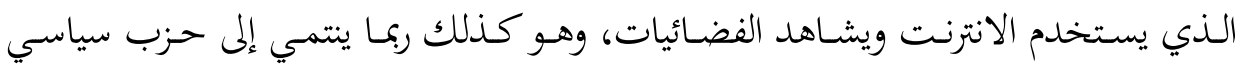

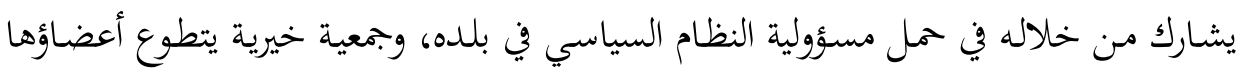

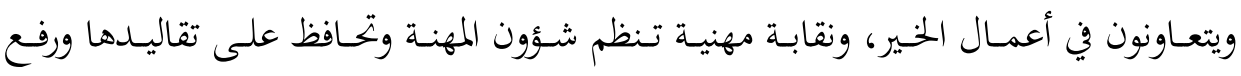
مستويات أدائها... إلخ. وإذا كان مـن السهـل أن يجـد الإنسـان هويته وانتمـاءه إلى عـدد مـن هـذه الدوائر المتداخلة في عالم يمتد على مستويات محلية وإقليمية، فإن الزمن الذي نعيشه اليوم، يسمح

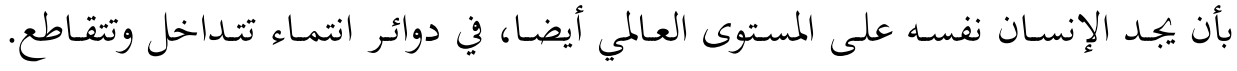

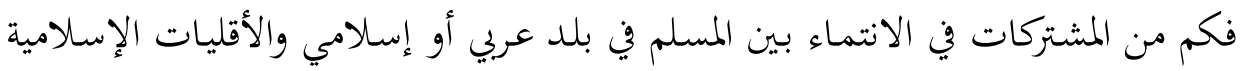

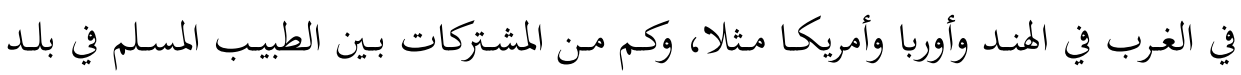

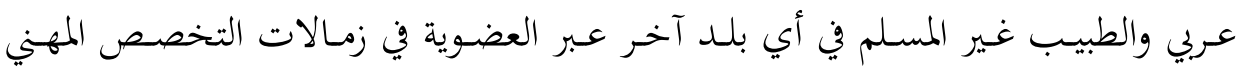
الدقيق، بما فيها من أدبيات وبجلات ومؤتمرات، وهكذا. 
ولو تحددت رؤية العالم عند الفرد المسلم المعاصر بموقعه هو في هذا العالم فإنه لن يجد نفسه

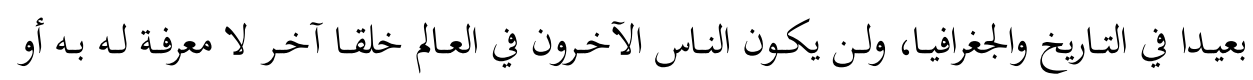

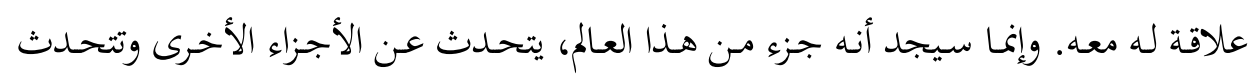

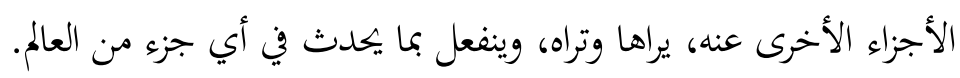
وبقدر ما تكون رؤية العالم لدى الفرد -اليوم- واضحة ومحددة بقدر ما يتحدد فهمه

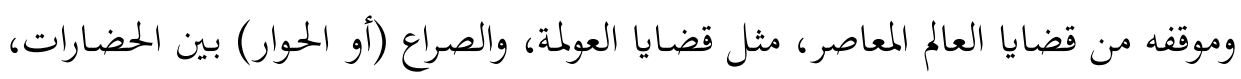

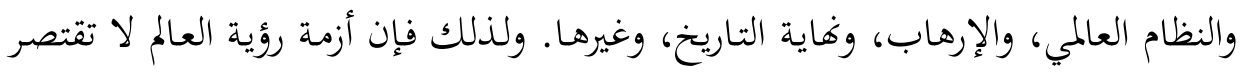

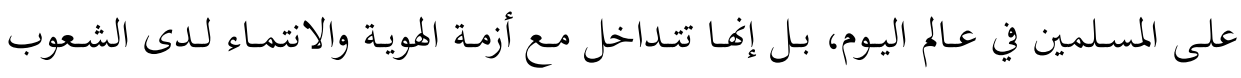

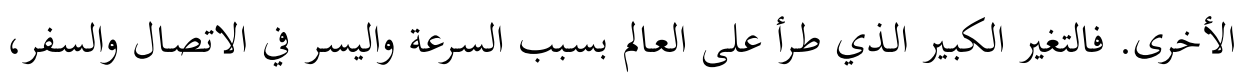
والتفاعل في الأفكار، والتداخل في المصالح والتزايد في مستويات الاعتمادية المتبادلة بين أسواق الإنتاج والاستهالك... كل ذلك أعاد النظر في أسئلة الهوية وتعريف الانتماء في

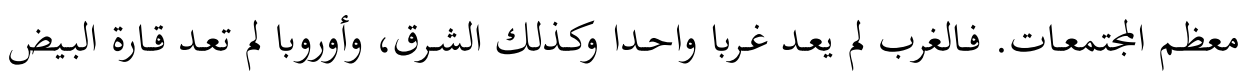

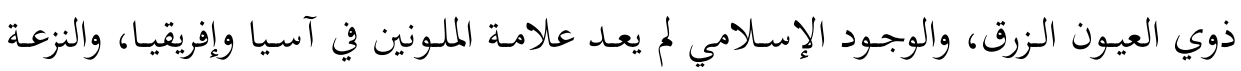
الإمبراطورية لم تعد خبرا في التاريخ.

إن وجود أزمة عامة في رؤية العالم، لا ينفي وجود بعض الفئات التي تزعم أهـا تملك رؤية للعالم تصلح للجميع، وتتوزع هذه الفئات على التحاهين متناقضـين تمامـا في رؤيتها

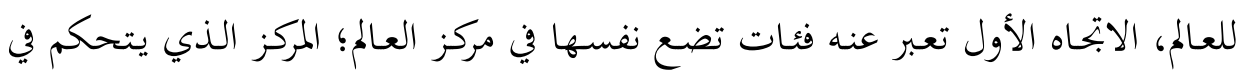
وجود الأطراف وفي حركة هذه الأطراف حول المركز، فهي تملك وحـدها الحقيقة، فبإذا

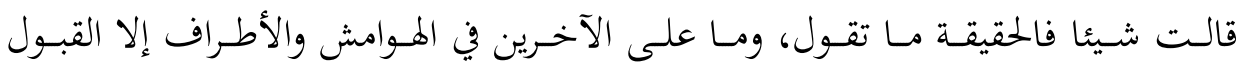

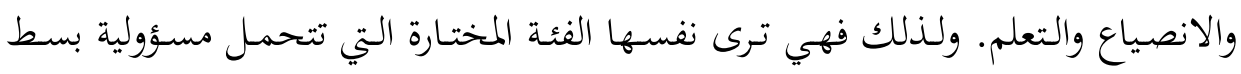

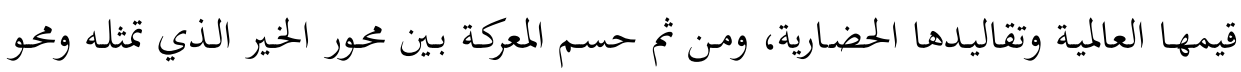

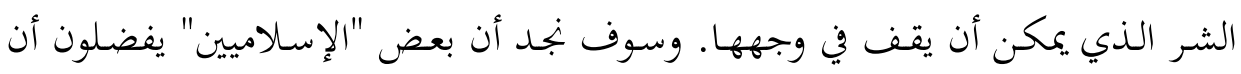
يصنفوا ضمن هذه الفئة. 


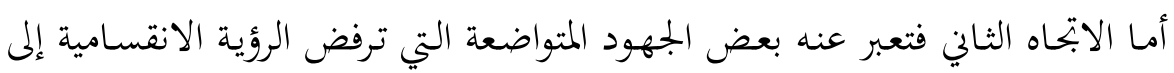

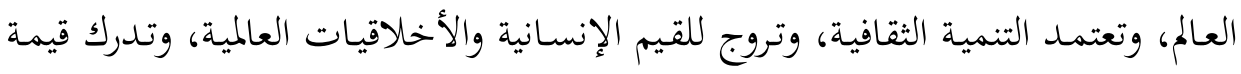

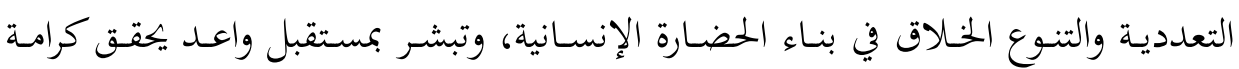

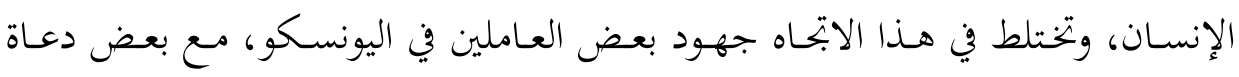

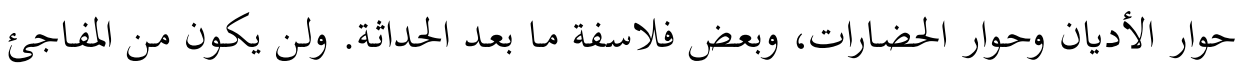

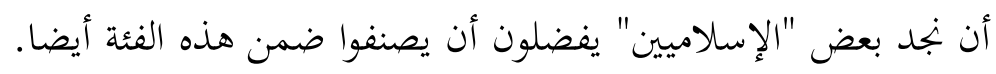
ترى أين يضع القارئ الكريم نفسه من حيث رؤيته للعالم؟ 